\title{
Reivindicaciones culturales y feminismos disidentes, una mirada nada normalizada
}

\author{
Cultural claims and postcolonial feminisms, \\ a non-normalizing outlook
}

Sonia Camps Giménez

Recibido: $13 / 06 / 2018$

Aceptado: 22/21/2019

\section{RESUMEN}

Las reivindicaciones de las culturas se desajustan del modelo ilustrado, en ese aspecto, el propósito de este ensayo es dilucidar de manera sucinta, las diferentes deconstrucciones y exclusiones culturales que nos encontramos en distintos paradigmas teóricos. La diferencia monopoliza el debate en un escenario multiétnico y globalizador. Los feminismos, diferentes entre sí, abogan por seguir reconceptualizando términos, y desmontando argumentos universalizadores, en base a la hibridación humana, en cambio, no diferencia las imbricaciones a lo largo de la humanidad. No obstante, las culturas son constantes creaciones, recreaciones y negociaciones de fronteras entre nosotros/as y el/la/los/las otro/a(s). No "somos" un determinado perfil cultural, sino un continuum mestizaje, donde, la diferenciación sexual construida como mecanismo de poder, ha subsumido a la mitad de la humanidad- las mujeres-, a la subordinación sistemática y por tanto, a la exclusión del poder. Este estudio aborda desde las fronteras, los diferentes feminismos a través de la metodología cualitativa de interpretación, apoyándose en diversos autores/as, figuras relevantes en los distintos planteamientos de la disidencia cultural.

Palabras clave: Cultura, diferencia, feminismos, identidad

\section{ABSTRACT}

The claims of cultures are disengaged from the illustrated model, in this aspect, the purpose of this essay is to elucidate, succinctly, the different deconstructions and cultural exclusions that we find in different theoretical paradigms. The difference monopolizes the debate in a multiethnic and globalizing scenario. Feminisms, different from each other, advocate continuing to reconceptualize terms, and dismantling universalizing arguments, based on human hybridization, however, does not differentiate the imbrications throughout 
humanity. However, the cultures are constant creations, recreations and negotiations of borders between us / as and the / the / the / the / others (s). We are not "a certain cultural profile, but a miscegenation continuum, where, the sexual differentiation constructed as a mechanism of power, has subsumed half of humanity - women -, to systematic subordination and, therefore, to the exclusion of the power. This study addresses from the frontiers, the different feminisms through the qualitative methodology of interpretation, relying on different authors / as, relevant figures in the different approaches of cultural dissidence.

Keywords: Culture, difference, feminisms, identity 


\section{INTRODUCCIÓN}

Las reivindicaciones de las culturas se desajustan del modelo ilustrado, en ese aspecto, el propósito de este estudio es dilucidar de manera sucinta, las diferentes deconstrucciones y exclusiones culturales que nos encontramos en distintos paradigmas teóricos. La diferencia monopoliza el debate en un escenario multiétnico y globalizador. Los feminismos, diferentes entre sí, abogan por seguir reconceptualizando términos, y desmontando argumentos universalizadores, en base a la hibridación humana, en cambio, no diferencia las imbricaciones a lo largo de la humanidad. No obstante, las culturas son constantes creaciones, recreaciones y negociaciones de fronteras entre nosotros/as y el/la/los/las otro/a(s). No "somos" un determinado perfil cultural, sino un continuum mestizaje, donde, la diferenciación sexual construida como mecanismo de poder, ha subsumido a la mitad de la humanidad- las mujeres-, a la subordinación sistemática y por tanto, a la exclusión del poder.

\section{PLANTEAMIENTO GENERAL}

El feminismo siempre ha estado en conflicto consigo mismo, la ya clásica disyunción entre feminismo de la diferencia y feminismo de la igualdad así lo corroboran. Es en este sentido, en el del conflicto, donde las diferencias culturales fundamentan nuestro análisis teórico, pues emergen del cuestionamiento del sujeto unitario "mujer", en contraposición con la diversidad femenina. En este aspecto cabe destacar, que el sujeto unitario "mujer" no puede representar a todas y cada una de las mujeres que reclaman y exigen un reconocimiento identitario. Se critica así, el esencialismo eurocéntrico, de mujer blanca de clase media, occidental, no ajena a influencias colonialistas. Este feminismo blanco, de clase media es cuestionado, pues resulta ciego a las 
diferencias de clase o raza. Así pues, desde diferentes feminismos, herederos de movimientos sociales que surgen en las últimas décadas del siglo $X^{1}{ }^{1}$, se reclama un lugar dentro del paradigma feminista. El feminismo poscolonial, feminismo decolonial o feminismo negro, serían testigos de estas corrientes ambos tres, cuestionan la cultura eurocéntrica, apostando por paradigmas que contravienen lo establecido, de algún modo, desean dar respuesta a una serie de cuestiones no resueltas desde el feminismo hegemónico, como la cuestión étnica o la influencia colonial. Así de esta manera, se diferencian y toman distancia de un feminismo que no les representa, y con el cual no se identifican. El feminismo negro, por ejemplo, tampoco es unitario, existen diferentes corrientes, desde el anglosajón, EE.UU. y Gran Bretaña, feminismo africano o caribeño, son algunos ejemplos, no obstante, los aúna las diferentes opresiones que sufren en sus respectivos territorios (Young, 2000). De este modo, podemos afirmar que a partir de muchos cuestionamientos posestructuralistas, y en particular, sobre el sujeto hegemónico, se erosiona y desmembran distintos mecanismos de poder, tal como Foucault nos apercibió. En este caso, pensadoras y activistas políticas, como Judith Butler, o María Galindo ponen en tela de juicio un arquetipo de mujer, blanca, burguesa, occidental, urbanita, en el que es inverosímil entender las múltiples contradicciones que los márgenes y fronteras actuales van cartografiando en un escenario múltiple y diverso. En este contexto, surge la tercera ola del feminismo ${ }^{2}$, donde entra en debate, la teoría queer, el trabajo sexual, la pornografía, la etnicidad, y los estudios poscoloniales en general.

\footnotetext{
${ }^{1}$ Los movimientos de liberación de la década de los 60’s como en el continente africano, países asiáticos, o por ejemplo la revolución en Cuba, dieron a luz a las políticas de la diferencia que rechazan los dos grandes ideales del liberalismo igualitario: la igualdad formal y jurídica y la neutralidad del Estado, en este sentido, el pacifismo, el ecologismo y el feminismo, las tres marías, movimientos sociales que evolucionarán a lo largo del siglo xx, concretamente, lo harán de modo aglutinador en referencia a la emergencia del ecofeminismo. Referir, que en este aspecto la variable ecologista no será tratada en este estudio, pues excede mi propósito, siendo la variable de identidad y cultura, las categorías analizadas.

2 Término introducido por primera vez por la autora Rebecca Walker, en su artículo Becoming the Third Wave y que incluye diversos feminismos
} 


\section{PLANTEAMIENTO PARADIGMA FEMINISMO NEGRO}

El feminismo negro nace en EE.UU, en un contexto histórico específico, la lucha por los derechos civiles, en el que la variable antropológica raza resulta estructural en la asignación de desigualdad y discriminación social hacia las personas afrodescendientes, adjudicando riqueza y derechos a los propietarios blancos. Proveniente de un sistema de esclavitud, el movimiento abolicionista en conjunción con el sufragismo de mediados del siglo XIX, da origen al feminismo negro en Estados Unidos, con la frase mítica “¿Acaso no soy una mujer? Sojourner Truth abre la antología, e Ida Wells, mucho antes que Rosa Parker, sufre la segregación, en este caso en el ferrocarril. Destacar el activismo político de Ángela Davis (1960) como respuesta al movimiento por los derechos

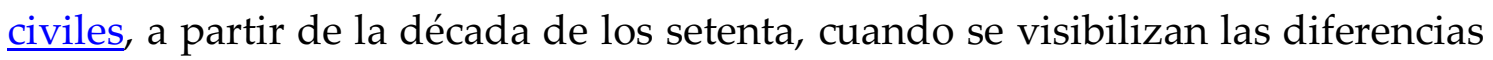
y luchas raciales, surgen a su vez, disidencias feministas dentro del feminismo negro, por la diversidad sexual, de Audrey Lorde, en todas ellas, la matriz de opresión es fundamentada por la raza, potenciada por la clase y el género, una quiasma de todas ellas. De este modo, otras autoras como bell hooks ${ }^{3}$, Ángela Davis, Alice Walker, o Patricia Hill Collins, conjugan las prácticas de acción política con la reflexión teórica. En concreto bell hooks hace referencia al extrañamiento de las mujeres negras estadounidenses, y afirma en voz propia que «las mujeres negras somos un grupo que no ha sido socializado para asumir el papel de explotador/opresor, puesto que se nos ha negado un "otro" al que podamos explotar $\mathrm{u}$ oprimir $>{ }^{4}$, frente a un feminismo conservador liberal que bajo el paraguas englobador de «todas las mujeres estamos oprimidas» resulta ciego a las formas en que el racismo y la posición de clase hacen específica la opresión de género para las mujeres negras. En ese sentido, el feminismo negro parte de la teoría de la interseccionalidad, Kimberlé Crenshaw

\footnotetext{
${ }^{3}$ No se trata de una falta ortográfica, sino que la autora bell hooks decidió escoger un nombre de pila que fuese en letra minúscula. ${ }_{4}^{4}$ Ibíd, p 49
} 
(1989).El feminismo negro, no es unitario, como hemos referido anteriormente, pues no agota la multiplicidad de posiciones étnicas del contexto estadounidense. Así, desde los años ochenta, el término «mujeres de color» fue desarrollándose en EE.UU. como un artefacto teórico y político capaz de aglutinar las opresiones comunes en torno al racismo que experimentan mujeres de procedencias nacionales y étnico-raciales distintas. Escritos mestizos y bilingües: textos como Borderlands ${ }^{5}$ adopta la multiplicidad y el mestizaje. Marcos imbricados y complejos que intersectan, desde la conciencia mestiza, una mixtura, que posibilita la existencia misma de co-imbricación, entre afrodescendientes, y/o mestizas, de este modo, la etnicidad articula el locus de enunciación de las mujeres racializadas.

Por otro lado, en cuanto a Europa, es en Gran Bretaña donde aparecen diversas teóricas del paradigma afrodescendiente. Poblaciones migradas desde los confines del imperio de la Commonwealth, y de otras partes del orbe mundial, en ese aspecto, las culturas nacidas dentro del Atlántico negro (Gilroy, 1993) llevan consigo el estigma de la violencia y de la esclavitud.

\section{PLANTEAMIENTO PARADIGMA DECOLONIAL}

El moderno sistema mundial nació a lo largo del siglo xvi. América como entidad geosocial- nació a lo largo del siglo xvi. La creación de esta entidad geosocial, América, fue el acto constitutivo del moderno sistema mundial. América no se incorporó en una ya existente economía-mundo capitalista. Una economía mundo capitalista no hubiera tenido lugar sin América. (Anibal Quijano e Immanuel Wallerstein, 1992, 583)

"La americanidad ha sido siempre, un elemento esencial en lo que entendemos como modernidad.La colonialidad se inició con la creación de un conjunto de estados reunidos en un sistema interestatal de niveles jerárquicos. Los situados

s 3 Anzaldúa, Gloria, Borderlands / La Frontera. The New Mestiza, San Francisco, Aunt Lute, 1987. 
en la parte más baja eran formalmente las colonias"', hablamos de la constitución de un patrón de poder, colonialidad del poder, que no sólo garantiza la explotación de unos seres humanos por otros a escala mundial, sino también la subalternización y obliteración de los conocimientos, experiencias y formas de vida de quienes son así dominados y explotados. (Aníbal Quijano,1992).

En este sentido, desde otros feminismos, como el feminismo decolonial, se analiza y se explora un nuevo giro epistemológico, desde la colonialidad del poder, que supone un patrón o matriz, y que estructura el sistema mundo moderno, en el que el trabajo, las subjetividades, los conocimientos, los lugares y los seres humanos del planeta son jerarquizados y gobernados a partir de su racialización. Por ello, se debe subvertir este patrón de poder colonial, estando aún presente en diferentes actitudes y manifestaciones de la sociedad actual. La colonialidad es el lado "oscuro" de la modernidad racional e ilustrada, la colonialidad y la modernidad constituyen dos lados de una misma moneda, es pues, una co-constitución. (Grosfoguel 2006,27)

No existe modernidad sin colonialidad, es posible según estas autoras, que las colonias fueron laboratorios del incipiente capitalismo burgués, por ello, se debe pensar desde parámetros del sistema mundo, desde la perspectiva geopolítica de poder, no desde el Estado nación, que no existe por sí mismo sino constituido con otras partes del mundo, y cuya vinculación colonial ha atravesado sus sociedades, en ambos sentidos. El sistema mundo moderno es producido en el proceso de expansión colonial europea que conecta por primera vez con diferentes territorios, dándole así una nueva escala global. Del germen imperialista colonizador, se articulan clasificaciones territoriales: Tercer mundo, países subdesarrollados, así, la geopolítica nombra y etiqueta con el objetivo de analizar lo extraño, lo exterior, lo colindante, a los sistemas ya establecidos de

· Ibid, p 584 
pensamiento racional," se propone una doble inversión a la idea del "pienso luego soy" cartesiano, a través del "Soy donde Pienso", donde los cuerpos y lenguas que están fuera de la epistemología hegemónica, son marcados a su vez por la corpopolítica". (Maldonado-Torres 2007, 193). En ese mismo sentido clasificatorio, Chandra Talpade Mohanty, cuestiona la nomenclatura colonial, con discursos como "la mujer del Tercer Mundo", una ficción política para hacer referencia a las mujeres no occidentales, y que manifiesta una clara intencionalidad discriminatoria.

La crítica al eurocentrismo desde la inflexión decolonial pasa por poner en evidencia el conocimiento sin sujeto, sin relaciones de poder, sin historia, un conocimiento desde ningún lugar, como 'la mirada de dios', descorporalizado y deslocalizado, desde una mirada de la razón científica, una mirada normalizadora (Foucault, 1977). Una mirada que confirma su objeto, de acuerdo con algún criterio jerárquico. El sujeto científico mide los objetos con escales que reducen la pluralidad. Conforme con la metáfora visual la visión es distante, unidireccional, quien observa es un ente concebido como puro y centralizado, así, de este modo, encontramos que el locus de enunciación de este paradigma, el de la perspectiva decolonial, en tanto, localizada y situada, en crítica absoluta al sujeto universal (Donna Haraway,1990) se encuentra dentro de la perspectiva feminista (postestructuralista) ${ }^{7}$.

La inflexión decolonial se piensa como un paradigma otro, que tiene en consideración la geopolítica y la corpopolítica. Todo conocimiento es un conocimiento situado histórica, corporal y geopolíticamente. El paradigma decolonial refiere una ética y una política de la pluriversalidad. En oposición a diseños globales y totalitarios en nombre de la universalidad, esta crítica es

\footnotetext{
identidad socialmente y temporalmente constituida, es decir, una identidad construida en tanto que resultado performativo de actos sucesivos, de sedimentaciones culturales, que se van hibridando en el espacio-temporal y así sucesivamente se conforman las identidades colectivas, las identidades no son fijas, como tampoco sus culturas, en ese sentido son dinámicas y performativas. (Butler,2014)
} 
compartida por el feminismo hegemónico, hijo no querido de la ilustración, por cuestionar precisamente a ese sujeto universal, que olvida a las mujeres. No es universal aquello que no tiene encuentra a la mitad de la especie humana, así como tampoco puede serlo, aquél que no ve a los otros y las otras porque no se encuentran en el lugar situado como hegemónico, y por tanto universal, desde el hombre blanco, anglosajón, burgués, heterosexual, en su mayoría protestante. En ese sentido, también el pensamiento decolonial es desobediente tanto epistémica como políticamente".

\section{PLANTEAMIENTO PARADIGMA POSTCOLONIAL}

Continuando con feminismos disidentes, en este caso desde el feminismo postcolonial, se ha denunciado la necesidad de crear discursos contrahegemónicos que estén a la altura de formular movimientos feministas globales y que no sólo se centren en el problema del género, sino que traten de manera unitaria otros condicionantes como la raza y la clase, o el género. Así, Gayatri Spivak, (1998) nos lanza el siguiente reto: ¿Puede hablar el sujeto subalterno?, por ello afirma, que el colonialismo es espacio de problematización, pues continúa teniendo efectos estructurantes de subjetividades, corporalidades, conocimientos, espacialidades y prácticas. El postcolonialismo encuentra sus raíces en el trabajo de Edward Said (2004), Orientalismo, en el que desde la mirada occidental define y conceptualiza Oriente, en cierto modo, lo inventa. En cuanto al concepto de lo subalterno, éste no designa una identidad pre- o para-capitalista, sino precisamente una relación de integración diferencial y subordinada dentro del tiempo del capitalismo. Dipesh Chakrabarty formula el problema de la siguiente manera:

“Las historias de lo subalterno escritas con atención a la diferencia no pueden constituir otra variante, en la larga y universalizadora tradición, de un 
esfuerzo de erigir a lo subalterno como el sujeto de las democracias modernas, es decir, de expandir la historia de lo moderno para hacerla más representativa de la sociedad como realmente es [....] Las historias de como este o aquel grupo en Asia, África, o América Latina resistió la penetración del capitalismo no constituyen, historia "subalterna" propiamente dicho" (Chakrabarty, 2000,95)

La identidad subalterna no es privilegiada, comparte una experiencia de desigualdad, más que un esencialismo de una identidad tal o cual, pues emerge de una historia de prácticas discriminatorias y exclusionarias. Dichas relaciones de subalternidad, marginalización y explotación son producidas por la hegemonía, de esa misma moderna cultura burguesa occidental, cuyo principio abstracto ético o epistemológico de reciprocidad o reconocimiento, "presunción de igual valor", al fin y al cabo, da como resultado un sujeto minoritario producido por la proximidad de diferencia, en vez de reciprocidad. Pero dentro de la visión de Spivak, el riesgo se traduce en convertir una experiencia concreta en el modelo normativo, hecho que puede ayudar a consolidar aun más la división internacional del trabajo ${ }^{8}$.

Los estudios postcoloniales, nos invitan a problematizar las fronteras. Sacan a la luz movimientos diaspóricos, interconexiones locales y globales que enlazan espacios en apariencia alejados. Un silenciamiento estructural de la subalterna dentro de la narrativa histórica capitalista del discurso del multiculturalismo. Es claro que la subalterna "habla" físicamente; sin embargo, su "habla" no adquiere estatus dialógico esto es, la subalterna no es un sujeto que ocupa una posición discursiva desde la que puede hablar o responder, en ese sentido la crítica postcolonial evidencia su heterogeneidad constitutiva. Así, de este modo Dipesh Chakrabarty, habla en particular de Provincializing Europe

\footnotetext{
\& «Cada día somos testigos de esta dinámica en nuestra disciplina, cuando vemos al migrante poscolonial convertirse en la norma, ocluyendo de esta manera, una vez más, al nativo». SPIVAK, C.G. Crítica de la razón poscolonial. Hacia una historia del presente evanescente. Akal, Madrid, 2015, p 254.
} 
(Provincializar Europa). Como indica Spivak, es el espacio en blanco entre las palabras, aunque el que se le silencie no significa que no exista, des-centrar el sujeto, resaltando cómo la idea del individuo -usualmente masculino- dotado de libre albedrío es una construcción ideológica que responde a una situación cultural, política, histórica y social específica que no es aplicable en todos los tiempos, todas las sociedades y todos los lugares (Ortner, 1995,185). Es por esta razón que la pregunta de Spivak en "¿Puede hablar el subalterno?" sigue teniendo tanta vigencia hoy día, esta indeterminación situacional, ¿Puede hablar el subalterno? ¿Qué taxonomía puede fijar tal espacio? Tanto si lo perciben ellos mismos como si no -dentro de la dialéctica del amo y el esclavodifícil tarea de reescribir sus propias condiciones de posibilidad como de imposibilidad. Foucault está en lo cierto al sugerir que "hacer visible lo nunca visto puede significar también un cambio de nivel, dirigiéndolo a uno a un estrato de material que hasta ahora no había sido pertinente para la historia y que no había sido reconocido como poseedor de algún valor moral, estético o histórico". Por todo ello, destacamos, que el feminismo postcolonial se encuentra dentro de los diferentes feminismos, y surge como respuesta a un feminismo universalista eurocéntrico, que desafía los parámetros culturales, refiriendo un discurso contra-hegemónico que no tiene en cuenta la variable raza o clase, ha denunciado la necesidad de crear discursos contra-hegemónicos que estén a la altura de formular movimientos feministas globales y que no sólo se centren en el problema del género, sino que traten otros condicionantes como la raza y la clase, o el género. Desde los feminismos, se plantea una re-configuración de los "sujetos del feminismo" desde la teoría de la interseccionalidad (Mohanty, 1988; Crenshaw, 1991), a partir de los feminismos diaspóricos, y desde el conocimientos situados, (Haraway, 1991) hacia un feminismo internacionalista. De esta manera, nos alejamos de la conceptualización de la diferencia como una construcción políticamente neutra que señala las diferencias entre grupos y 
entre el mismo grupo, para utilizarla como diferencia jerarquizada, es decir, un problema relacionado con la "posicionalidad" y la asimetría (Anthias, 2002),9 ahora bien, las diferenciaciones relativas al género, al origen nacional (asociadas a atribuciones culturales) y a la posición socioeconómica funcionan como marcadores de diferencia en las prácticas y discursos, generan violencia epistémica: categorías como la de "historia" o "mujer" son eurocéntricas y sin embargo se autoinstituyen como universales, hecho que constituye materialmente a la "otra" como subalterna.

\section{PLANTEAMIENTO PARADIGMA MULTICULTURAL}

En realidad, el término "multiculturalismo" es de invención reciente, empezó a utilizarse, a partir de un congreso sobre "Multiculturalism, Minorities and Citizenship", celebrado en Florencia, en abril de 1996, así, en la década de los noventa, tras el hundimiento del telón de Acero y el desmoronamiento de la Unión de Repúblicas socialistas soviéticas (URSS), comienza problematizarse el concepto de Estado-nación, y cuestionando del proceso de globalización, criticando el modelo monocultural de occidente. En un contexto de cambios, protagonizados por las demandas de grupos específicos de personas: migrantes, minorías étnicas, nacionales, culturales, así como las mujeres, potenciándose por efecto de la globalización. No obstante, su origen responde a la emergencia en la década de los sesenta como el pacifismo, el ecologismo y el feminismo, grupos sociales críticos, asicomo el desarrollo de los Derechos Humanos y su influencia política. Se reclamaba la atención de las especificidades de colectivos vulnerables. Su respectivo reconocimiento, cuestionando las relaciones de dominación, solicitando una transformación de las instituciones de forma que estos grupos sociales también deben ser

\footnotetext{
9 En Marisela Montenegro Martínez; Caterine Galaz Valderrama; Laura Yufra; Karla Montenegro Quitana, disponible en https:/ / ddd.uab.cat/pub/athdig/athdig_a2011m7v11n2/15788946v11n2p113.pdf
} 
representativos, se pretendía la participación en su conjunto. (Neus Campillo, 2001,194).

En ese sentido, es posible la aceptación diferentes prácticas culturales, su participación en el espacio público, donde la identidad cultural se plantearía en términos de reconocimiento de derechos identitarios. En cualquier caso, las culturas y las sociedades no son monolíticas, sino dinámicas, y encontramos un común denominador en todas ellas, el persistente interés por el posicionamiento y control social y político de las mujeres, niños y niñas. Las culturas y sociedades en constante interacción, han puesto el punto de mira comparativo en la posición y situación social de las mujeres.

Temas tan controvertidos como el control de los cuerpos femeninos, la sexualidad y la reproducción de las mujeres, se han consolidado como un tema recurrente en todas y cada una de ellas. Somos depositarias de las tradiciones culturales, nos asignan roles y estereotipos que construyen un arquetipo de mujer, un modelo realizado a imagen y semejanza de un sistema androcéntrico, que posee el poder de y sobre las mujeres de casi todo el planeta, no nos llevemos a engaño, es por ello que debemos reapropiarnos de los cuerpos que el patriarcado nos ha robado. Cuestiones como el matrimonio, el nacimiento, la muerte, los rituales del sexo, etc, han sido temas nucleares en la existencia humana. La centralidad de la esfera sexual y reproductiva, ha sido y continúa siendo objeto de controversia, en ese sentido, su regulación marca una línea divisoria entre naturaleza y cultura, (phisis y nomos). (Benhabib, Sheyla, 2006,145-146). ${ }^{10}$ La exclusión del cuerpo asignado al ámbito de lo "natural", en oposición al de mente, relacionado con lo cultural y racional, ha supuesto temas relevantes en debates sobre el orden y control social, por tanto, la corporeidad

\footnotetext{
10 En "Las reivindicaciones de la cultura la igualdad y la diversidad en la era global". Buenos Aires: Ed Katz
} 
femenina acaba siendo receptora de y disciplinada por las sociedades y sus culturas.

Retomando el multiculturalismo como expresión y respuesta a los movimientos sociales dentro de un contexto de globalización, Charles Taylor, en su célebre ensayo sobre el "multiculturalismo y la política de reconocimiento" hace ver la importancia del reconocimiento debido como "una necesidad humana vital", pues la falta de reconocimiento o el falso reconocimiento de alguien, impuesto por "otros" desde un punto de vista despectivo y denigrante, puede causar fuertes daños y ser un medio efectivo de control y dominación, en la medida que esa imagen inferior sea internalizada, a tal grado que la "propia autodespreciación se transforma en uno de los instrumentos más poderosos de su propia opresión"11

Charles Taylor describe dos modelos, por una parte, uno representa la política de la dignidad igualitaria (canasta idéntica de derechos e inmunidades) y otro la política de la diferencia, en la que se enfatiza que todos somos dignos de respeto, y que por tanto debemos ser tratados de la misma manera, Taylor relaciona este modelo con Rousseau y Kant. Taylor $(1993,61)$ El autor afirma que la identidad dominante ha asimilado a la identidad del individuo/a, lo cual conduce a un problema de legitimidades, La autenticidad de estas identidades ha estado obstaculizada por la identidad dominante. Charles Taylor afirma:

“Estos dos modelos de política que comparten el concepto básico de igualdad de respeto entran en conflicto. Para el uno, el principio de respeto igualitario exige que tratemos a las personas en una forma ciega a la diferencia. La

\footnotetext{
"La interiorización de una imagen inferior y despectiva de sí misma, remite entre sus causas principales a procesos de opresión o dominación inducidos por sociedades patriarcales. Según esta idea, su propia autodespreciación se transforma en uno de los instrumentos más poderosos de su propia opresión". Así mismo se arguye que a partir de 1492 los europeos, "en las colonias laboratorio de la modernidad" proyectaron una imagen de tales pueblos como inferiores, "incivilizados" y mediante la fuerza de la conquista lograron imponer esta imagen a los conquistados". Charles Taylor, Multiculturalismo y la "política del reconocimiento",Fondo de Cultura Económica, Sevilla, 2003, p. 44. También Honneth habla del daño moral que puede infligir la falta de reconocimiento por los "otros ", en la autorespeto, autoestima, y autoconfianza de las personas y colectivos. Axel Honneth, La lucha por el reconocimiento. Por una gramática moral de los conflictos sociales, trad., Manuel Ballestero, Crítica, Barcelona, 1997.
} 
intuición fundamental de que los seres humanos merecen este respeto se centra en lo que es igual en todos. Para el otro, hemos de reconocer y aun fomentar la particularidad. El reproche que el primero hace al segundo es, justamente, que viola el principio de no discriminación. El reproche que el segundo hace al primero es que niega la identidad cuando constriñe a las personas para introducirlas en un molde homogéneo que no les pertenece de suyo. La queja va más allá (...) hacia el reflejo de una cultura hegemónica" $(1993,67)$

Se lucha es no sólo por el reconocimiento de la diversidad, sino también por la preservación y la valoración positiva de estas culturas distintas. Ello implica que tengan derechos como, por ejemplo, el de regirse bajo reglas de 'usos y costumbres' propios de su comunidad. Taylor propone que todas las culturas deben ser reconocidas como valiosas y dignas de igual respeto, puesto que todas ellas tienen "algo importante que decir a todos los seres humanos" (1993, 98).

Algunas personas emplean el término "multicultural" de una manera amplia para englobar una extensa gama de grupos sociales no étnicos que, por diversas razones, han sido excluidos o marginados del núcleo mayoritario de la sociedad. Este uso es particularmente frecuente en Estados Unidos, donde los partidarios de un curriculum "multicultural" están a menudo aludiendo a los esfuerzos por invertir la exclusión histórica de grupos como los discapacitados, los gays, y las lesbianas, las mujeres, la clase obrera, los ateos o los comunistas (Kymlicka, 1996,35). Así, la sociedad multicultural deviene además, de las migraciones familiares e individuales, que van conformándose en diferentes grupos étnicos y que conviven con la mayoría nacional, a su vez diversa. Estos últimos no son lo suficientemente representados, por lo cual exigen mayor reconocimiento político y social, pretenden que las leyes sean más permeables a las diferencias culturales. Las sociedades modernas comparten una misma cultura, en la medida que participan de la misma vida social industrializada y 
avanzada, empero no serían estados multiculturales. No obstante, Kymlicka afirma un multiculturalismo derivado de diferencias, por un lado nacionales, y por otro, étnicas, en este sentido, las identidades culturales son concebidas como sinónimo de nación o pueblo:

“Es decir, como una comunidad intergeneracional, más o menos completa institucionalmente, que ocupa un territorio o una patria determinada $y$ comparte un lenguaje y una historia específicas. Por tanto, (un Estado multinacional) bien si sus miembros pertenecen a naciones diferentes (un estado multinacional) bien si éstos han emigrado de diversas naciones (un Estado poliétnico)" Kymlicka, (1996,36)

Por otra parte, se distingue lo que suele denominarse -nuevos movimientos sociales - personas que han sido marginadas dentro de la sociedad nacionales, $\mathrm{O}$ de su propio grupo, personas que manifiestan distinto activismo social. (Pah, mareas ciudadanas, etc), vinculados a su vez, a minorías nacionales y/o grupos poliétnicos migrantes, es decir, minorías nacionales o grupos de migrantes mantienen en sus filas, a su vez, diversos colectivos: discapacitados, mujeres, diversidad sexual, étnica, religiosa entre sus miembros. La hetereogeneidad es la norma, por muy homogéneo que sea un grupo, siempre alberga diferente diversidad entre sus miembros como ya hemos referido, es decir, no plantean reivindicaciones étnicas concretas, en tanto a otras naciones donde grupos étnicos sí plantean esto, pues constituyen entidades más compactas, que mantienen su cultura y son conscientes de sí mismas. Kimlicka, $(1996,58)$

La argumentación de la justicia relativa a considerar estos derechos especiales para estas minorías, ocurren si existen desventajas relacionadas con la pertenencia cultural, y si tales derechos sirven para corregir dicha desventaja, por tanto el alcance legítimo de estos derechos variará según las circunstancias. Kimlicka $(1996,154)$ 
Las políticas de reconocimiento, de la identidad, asícomo los debates de las diferencias, tienen sus precedentes en las décadas de los sesenta y setenta del siglo $\mathrm{XX}$, el feminismo, pacifismo, ecologismo, las tres marías, auspiciaron un caldo de cultivo favorable a las diferencias culturales, que se subordinaba a un problema de cultura y supuestamente nada tenía que ver con la economía política. El resultado fue la indefensión ante el avance del libre mercado. Un fundamentalismo que no tenía barrera alguna que lo cuestionase, puesto que las diferencias existentes eran producidas por la cultura. Bajo este paraguas se ocultaban cuestiones de gran relevancia para la consecución de una equidad social. Las políticas de redistribución fueron relegadas en pro de políticas de reconocimiento, auspiciadas desde la perspectiva multiculturalista.

El feminismo aparece vinculado a las diferenciaciones de grupo, y en ese sentido comparte con el multiculturalismo perspectivas de reconocimiento como grupo social que sufre desigualdad. Iris, Marion. Young, apuesta por la heterogeneidad ante la homogeneidad. Otro autor, Michael Walzer, sostiene que la "política de la diferencia" gira en torno a las diferencias religiosas y étnicas, aunque puede ampliarse a la clase, a la raza, o al género. Los autores mencionados comparten la preocupación por la justicia social. Se entiende pues, que el multiculturalismo pretende una mayor igualdad, social y económica, de una política participativa (Agra, 2000,136). El multiculturalismo, en ese sentido, se dirige a situaciones de pluralismo poliétnico, como multinacional, incluso hay otra concepción que va dirigida hacia grupos como las mujeres, la clase obrera, o los/as homosexulaes. "Se entiende pluralismo como la traducción democrática de una propuesta de resolución de estos problemas de entendimiento entre culturas. El pluralismo es diálogo, consistiría en "reconocer, apreciar y no violar la alteridad del "Otro" (Bernstein, 1991, 21)12.

"2 Citado por Neus Campillo, 2001. “La pluralidad cultural humana," Filosofía Social. pág 202. 
En otro orden de ideas, se evidencia que todas las culturas se han preocupado por el control de la sexualidad y la reproducción de las mujeres, tema recurrente históricamente. Ya desde la Grecia clásica, el estatus de las mujeres, ha sido un debate filosófico, Sócrates, Platón o Aristóteles anduvieron con estrategias hereditarias y eugenésicas. En ese aspecto, este complejo diálogo multicultural que persiste en la mercantilización de mujeres por parte de los varones de la especie, en la figura del matrimonio, o en las guerras, periodo convulso donde las mujeres sufren todo tipo de vejaciones, violencias y apareamientos de diversa índole, como consecuencias de situaciones extremas, y que como grupo oprimido, han soportado sobre sus cuerpos toda la violencia ejercida sobre ellas, con indolencia, o con resistencias. Las distintas prácticas de intercambio que se han llevado a cabo a lo largo de la humanidad detallan múltiples ejemplos del estatus que se ha otorgado a las mujeres a lo largo de la historia. Empero no es la única reflexión que afirmamos en este escrito, se trata de entender de qué manera, diferentes prácticas (la regulación del sexo, la muerte o el nacimiento) han existido en nuestras vidas entorno al núcleo mismo de la misma. Es decir, lo más íntimo y privado, en donde naces y te haces. La esfera privada, es el punto de partida, a partir de ahí nos desarrollamos en una simbiosis comunicativa interpelándonos continuamente.

Según refiere Okin, (1999, 12-13)"la esfera de la vida sexual y reproductiva es un foco central, en la mayoría de las culturas humanas."La regulación de ello, se transforma en línea divisoria entre naturaleza y cultura, phisis y nomos. Para esquematizar esta configuración lo haremos diferenciando esta esfera en tres estadios. En primer lugar, hablaríamos de conciencia moral y religiosa, en segundo término, giraría sobre libertades económicas (intercambio de bienes y servicios, libertad de contrato, trabajo asalariado ${ }^{13}$, por último, y la más invisibilizada sería la satisfacción de necesidades cotidianas de la vida, como la

${ }_{13}$ Una de las 4 notas que debe existir en el trabajo asalariado es la voluntariedad 
sexualidad, la reproducción, el cuidado de niños/as y ancianos/as ${ }^{14}$. Bien, el conflicto emerge cuando la primera esfera, denominada de conciencia religiosa, dentro de la categorización moral se instrumentaliza a favor de justificar ciertas acciones sobre la tercera esfera, la esfera de ámbito doméstico. Afectando las actuaciones y conductas dentro del hogar donde una/uno vive su máxima intimidad y el ejercicio de libertad que se presupone. En ese caso en ocasiones el derecho de conciencia de sujetos masculinos entran en conflicto con las sujetos femeninas, y con las niñas y niños, en este universo que se halla en esta esfera, y la vulnerabilidad mayor se encuentra en estos últimos, pues no son protegidos precisamente por estas categorizaciones sociales, al estar bajo el influjo de creencias, acerbos culturales que de un modo $\mathrm{u}$ de otro rigen la vida de las personas. (Benhabib, 2006)

Es precisamente en estas esferas, donde el diálogo intercultural trasluce mayores diferencias. Así, por ejemplo, Bihikhu Parekh ${ }^{15}$ refiere doce prácticas que provocan desconciertos en la evaluación intercultural, dos sobre códigos de vestuario: turbante sikh (minoría religiosa indú) en este caso se enfoca al género masculino, y el pañuelo islámico hijab, que tanta controversia ha suscitado en occidente, tanta como la circuncisión femenina, en sus diferentes grados, asicomo la masculina, que no se encuentra representado en este debate tan enconado. Si proseguimos con la numeración de ejemplos, encontramos laceraciones y otras prácticas ornamentales en diferentes partes del cuerpo, los matrimonios atípicos dentro de la perspectiva europeísta, como el ejercicio de la poligamia, matrimonios arreglados, uniones conyugales con menores. Diferentes enlaces matrimoniales dentro de diferentes grados de parentesco. Proseguimos con la práctica musulmana de la retirada de las niñas de la educación mixta en el deporte, las reticencias y negativas de colectivos como el

\footnotetext{
${ }^{14}$ En Benhabib 1992:107-109),citado en Los malestares de la Cultura $(2006,146)$

${ }^{15}$ Citado en Benhabib $(2006,147)$
} 
"gitano" y el "amish" en cuanto el envío de sus hijas/os a las escuelas públicas, sobre todo después de una determinada edad. En España, desde hace 30 años los gitanos y gitanas acuden a las escuelas públicas, sin embargo, es el colectivo de estudiantes con el porcentaje más alto de abandono escolar temprano ${ }^{16}$. Destacamos como último ejemplo, el ritual fúnebre hindú, encontrándonos con la práctica de la cremación, praxis cultural en el que las mujeres viudas de los finados eran asimismo arrojadas a la pira funeraria ${ }^{17}$.

Podemos comprobar que estas prácticas culturales no son normativas desde el laicismo del Estado/nación, desde países que se encuentran en el hemisferio Norte. Empero, encontramos paralelismos en estas culturas, en periodos históricos ya lejanos y también otras prácticas que no andan muy lejos de un pasado más reciente. Si reflexionamos sobre este asunto, coincidimos, desde luego, en la afectación del estatus de las mujeres, a su limitación de autonomía, a la escasa o nula libertad de acceso a espacios, los cuales se le restringen, se las marcan, se les impiden mediante barreras simbólicas infranqueables, o simplemente se las eliminan. El robo del espacio femenino. Una subordinación u opresión que estructura las relaciones entre los sexos, diferencias estructurales que crean desigualdad social. Se dan en el ámbito público y en el privado. Este no-reconocimiento, esta infravaloración, o estatus subordinado también en la esfera privada se da prácticamente desde los albores de la humanidad. En todas las culturas y prácticamente en todos los periodos históricos.

Se relacionan estas prácticas culturales a lo más recóndito de la identidad, desde la conciencia expresada, por tanto se relaciona con bastante frecuencia con motivos que emergen de la naturaleza misma de sus culturas. Por ello, están enraizadas y genera vulnerabilidad psíquica. Así, en muchos casos, las

\footnotetext{
${ }_{16}^{16}$ Según la ONG Fundación Secretariado Gitano, un 64\% del alumnado gitano de entre 16 y 24 años no concluye los estudios obligatorios frente al $13 \%$ del conjunto del alumnado. Veáse https://www.gitanos.org/que-hacemos/areas/educacion/en cifras.html

${ }_{17}$ Afortunadamente hoy en día se considera un delito, así pues, las mujeres no acompañan al cortejo fúnebre, únicamente los hombres forman su composición.
} 
diferentes invasiones o penetraciones en sus respectivos entramados culturales, se perciben y se interpretan como auténticas violaciones o profanaciones. La vertiente más radical sería el fundamentalismo.

Multiculturalismo, identidad, y reconocimiento, no deben desvincularse de las reflexiones que se produjeron en los años noventa en Estados Unidos, y en el que el feminismo está firmemente implicado. La categorización de la igualdad /diferencia, su implicación teórico práctica para el género y el feminismo. El feminismo ya no puede seguir con un reduccionismo, ha de ampliar su campo teórico práctico. Las interacciones clase, raza, sexo, nacionalidad, etnicidad, están presentes. En este sentido, planteamos la argumentación teórica de esta investigación. Según Nancy Fraser (1995) hay que evitar dos tendencias. Por una parte, el multiculturalismo, en aquellas versiones en que el reconocimiento de todas las identidades y diferencias son merecedoras de reconocimiento, por otro lado, existiría un antiesencialismo indiscriminado, que considera ficciones represivas identidades y diferencias, relativismo cultural radical (esencialismos versus antiesencialismos posestructurales). Según Fraser la finalidad de la lucha es la creación de formas públicas multiculturales que reconozca una pluralidad de formas diferentes e igualmente valiosas de ser humano. Se debe rechazar la versión pluralista del multiculturalismo, como concepción de entender la diferencia "unilateralmente positivo", celebra la diferencia de un modo acrítico sin cuestionar la desigualdad. ${ }^{18}$ En definitiva, Fraser indica que el debate sobre la diferencia en el seno del feminismo se desarrolla en dos fases. La primera de los años sesenta a los ochenta aproximadamente. El debate giraba en torno al "feminismo de la igualdad" y el "feminismo de la diferencia", y el centro del mismo es la "diferencia de género". El feminismo de la diferencia o cultural que aparece en estos años comparte la idea de que la diferencia de géneros es real y

${ }_{18}$ En Nancy Fraser ( Multiculturalidad y equidad entre los géneros: un nuevo entorno de los debates en torno a la diferencia en EE.UU, (pp35-55) recuperado de: http:/ / www.mujeresenred.net/IMG/pdf/Multiculturalidad y equidad entre los generos.pdf 
profunda, la más importante de todas las diferencias. Las mujeres "como mujeres" comparten una identidad común, de ahí que haya que reconocer, no minimizar o abolir, las diferencias de género, la diferencia adquiere aquí, pues, un sentido afirmativo, que incide en los lazos de "sororidad". Así pues el movimiento feminista se divide en dos versiones distintas, dos formas de entender la justicia y la igualdad. (Agrá, M Xosé, 2000,151).Las mujeres sufren falta de reconocimiento por la diferencia sexual, pues esta diferencia las objetiviza, y también sufre de una inadecuada distribución, pues es bien conocida la diferencia o brecha salarial entre las féminas de todo el mundo. Así, redistribución y reconocimiento en calve de género, además de cultural, desde la perspectiva transformadora de una sociedad socialista deconstructivista, en la que se eliminan las diferencias de grupo.

\section{ACTUALIDAD}

En la actualidad, el centro del debate en el feminismo se desplaza hacia las "diferencias entre las mujeres", el cual viene propiciado por las críticas de mujeres de color, lesbianas quienes no se sienten interpeladas en ese modelo supuestamente universal de mujeres occidentales, heterosexuales, blancas, de clase media y anglosajona. Es decir, se cuestiona el feminismo cultural o de la diferencia, pues invisibiliza las diferencias reales entre mujeres. Ambos feminismos, tanto el feminismo de la igualdad como el de la diferencia habían hecho generalizaciones equivocadas, es decir, habían eliminado otros ejes de subordinación, menos el género, (tal vez, la excepción sería el feminismo socialista que sí tenía en cuenta la clase). Estas críticas coinciden con la expansión de "los nuevos movimientos sociales", en este contexto, cada movimiento politiza de una manera diferente, "interfiriendo más que coexistiendo". En los noventa, se atiende fundamentalmente a las "diferencias 
entre mujeres", e introduce elementos correctores evitando la homogeneización y el esencialismo. Es en este momento, cuando el "antiesencialismo" y el "multiculturalismo" ofrece alternativas, el problema radica, en que no se realiza desde una base de "igualdad social" Fraser, (1995). La crítica al antiesencialismo por deconstruir estas concepciones deviene en escepticismo al reconceptualizar identidad y diferencia como producciones discursivas "ficciones". Tanto N. Fraser como S. Benhabib, alertan de sus implicaciones políticas, pues consideran "las reivindicaciones de la identidad en términos ontológicos, y no se plantean como una identidad dada. En ese aspecto, se relaciona con las estructuras sociales de dominación y con las relaciones, con relaciones sociales de desigualdad" Fraser (1995:49). S. Benhabib (1996) arguye sobre la identidad y su vinculación con los feminismos postestructuralistas, influidos por pensadores franceses, "los maestros de la sospecha", tales como Liotard, Derrida, Foucault, Irigaray y Cixous.

Desde el planteamiento multiculturalista, en este caso, Celia Amorós, nos habla de «multiculturalidad ilustrada», si pensamos que "El feminismo es en gran parte un descendiente del liberalismo que está alimentado por una crítica similar de las posiciones inmutables y de las jerarquías tradicionales, comprenderemos mejor las políticas de las diferencias de distintos autores/as, tales como Sheyla Benhabib, (2006) o Charles Taylor (2010). Sin embargo, según sea el paradigma decolonial, o poscolonial, se encontrarían, pues, escorados en un Estado Occidental, este hecho, limita las energías subversivas:"liberalism multiculturalism", "Soy donde Pienso" y en el que de acuerdo con Bhabha (1997), existe el peligro de una política de identidad que puede quedar atrapada "incapaz de participar en una política transformativa, colectiva" sino en cierto sentido colusorio con sus propias condiciones sociales de producción y 
reproducción como sujeto subalterno o minoritario" Bhabha $(1997,452)$. Sería, entonces, una identidad "plasma".

Existen diferencias entre la perspectiva decolonial y la poscolonial, que se orientan a su fundamentación cartográfica e histórica; la perspectiva decolonial en cuanto la diferencia colonial, que se remonta a la colonización de América Latina y el Caribe por las primeras potencias europeas España y Portugal, entre los siglos XVI y XIX, en el contexto de la primera modernidad; mientras que los estudios postcoloniales refiere la colonización de Asia y África del XVIII al XX, por parte de las potencias del norte europeas (Francia, Inglaterra, Alemania) en el contexto de la segunda modernidad. (Eduardo Restrepo Axel Rojas, 2010:24) ${ }^{19}$ De este modo, la inflexión decolonial nos refiere experiencias y trayectorias intelectuales y políticas propias de América Latina (el temprano colonialismo hispano-lusitano y corrientes intelectuales como la teoría de la dependencia y la diferencia colonial, paradigma otro, pensamiento fronterizo, geopolítica del conocimiento y sistema mundo moderno/ colonial, son algunas de las más evidentes. (Castro-Gómez y Grosfoguel 2007: 14). Desde la colonialidad del ser, en el sistema mundo, se inferiorizan seres humanos, marginalizando e invisibilizando sistemas de conocimiento, desde un patrón de poder global para su explotación en aras de la acumulación ampliada del capital (Escobar 2003, Grosfoguel 2006, Grosfoguel y Mignolo 2008). Desde el paradigma postcolonial, en cambio, aborda la subalternidad, como categoría analítica fundamental. Por otra parte, la cuestión étnica también es representativa, también en el paradigma postcolonial, jerarquizando grupos humanos.

En ese sentido, Fanon (1963) refiere en su libro Los Condenados de la tierra: “En las colonias, la infraestructura es igualmente una superestructura. La causa es consecuencia: se es rico porque se es blanco, se es blanco porque se es rico"

\footnotetext{
- Eduardo Restrepo Axel Rojas (2010) Inflexión decolonial: fuentes, conceptos y cuestionamientos. Universidad del Cauca, Popayán, Colombia. Editorial Universidad del Cauca.
} 
$(1963,34)$, emulando la metáfora marxista de la infraestructura y la superestructura.

Cabe decir, que el racismo y el colonialismo como fenómenos van unidos, y producen efectos en la producción de las subjetividades del sujeto colonial (colonizador y colonizado). Así, el eurocentrismo colonizador ha impuesto un proyecto civilizatorio particular como "ethos universal". De este modo, se entiende que también el feminismo occidental hegemónico, mantiene prácticas colonizadoras, pues parte del mismo locus de enunciación de mirada universalizante, y homogeneizante, excluyendo las diferencias en un cajón de sastre. Desde la descolonización del feminismo, se recomienda superar la codificación colonial de la diferencia a la vez del ethos de la objetivación y universalización que domina el pensamiento moderno. Frente a esta representación neocolonial y claramente racista, se exige la consideración de las mujeres del "Tercer Mundo", las subalternas, como sujetos de acción política, sujetos sociales constreñidos por una variedad de estructuras de dominación, entre las cuales una es el género, que se articula con otras igual de relevantes en las vidas de las mujeres, el racismo, la pobreza, etc. (Liliana Suárez, 2010)

Desde las distintas caras de opresión, (Iris Young 1.997) que sufren las mujeres racializadas y que unifican malestares, emergen estos feminismos disidentes y críticos, pues no se sienten identificados con un feminismo que se entiende como descendiente de la tradición ilustrada. El feminismo de la Igualdad, y el de la Diferencia se sitúa demasiado lejos del escenario de lucha y reivindicación por los derechos civiles de los/las descendientes del cultivo del algodón, o de las violencias ejercidas sobre mujeres de otras culturas. De cualquier modo, en los países de corte occidental, el paradigma neoliberal se fundamenta en la supuesta neutralidad del Estado, que se traduce en un apoyo a la propia idiosincrasia, es decir, a la cultura dominante, pues los instrumentos utilizados 
para evaluar han sido creados, valga la redundancia, por la cultura dominante propiamente dicha, lo que supone una desventaja para las personas culturalmente diferentes; Taylor (1994), I, Young (1997). En este aspecto, coincido en la argumentación de Audrey Lorde (2002)“Las herramientas del amo nunca destruirán la casa del amo", pues no se trata del principio de igualdad, lo que se pretende, pues sería un principio de igualdad jurídico basado en la ideología liberal, en la ideología del $a m o^{20}$, tampoco se trata de integración, ni asimilación. De lo que se trata es de diferenciación.

Así, conceptos como ciudadanía y nación, están atravesados por las colisiones, las contradicciones y los desequilibrios que. El tiempo «homogéneo y vacío» del que hablaba Walter Benjamín articula la historia de la modernidad, sin embargo, no es posible más que en una continua «hibridación», no se puede pensar en términos lineales, sino que se plantea más bien como un marco constante con los «lugares» involucrados en este proceso de producción.

\section{CONCLUSIÓN}

A la luz de lo expuesto en las páginas precedentes, hablar de praxis feministas en contextos globales supondría cambiar la unidad de análisis de la cultura local, regional y nacional por las relaciones y procesos entre culturas. Asentar el análisis en praxis feministas locales, particulares, es necesario, pero también necesitamos comprender lo local en relación con procesos transnacionales más amplios. Destacar que la globalización ha supuesto un vertiginoso cambio en el mundo y en las relaciones que se establecen tras la coexistencia de diversas culturas en los mismos territorios. Es un hecho y se le conoce con el término de multiculturalidad, en ocasiones esta diversidad cultural es repartida en compartimentos estancos, lo cual deviene en una segmentación de la sociedad

\footnotetext{
20 Se alude al amo y el esclavo, en referencia a la metáfora hegeliana, de ideología burguesa.
} 
todavía más. En ese aspecto, nos enfrentamos con marcadores de diferencia imbricados en una compleja interseccionalidad y que se actualizan performativamente en las prácticas cotidianas, estando estructurados por complejas articulaciones de estamentos legales, espacios físicos, relaciones, etc. (Romero Bachiller y García Dauder, 2003; Romero Bachiller, 2006). Éstas marcas contribuyen a constituir al racismo, la diferenciación étnica, el sexismo, entre otros, como sistemas interconectados de dominación donde uno sostiene al otro y viceversa (Maynard, 1994)"21.

La historia es sexuada, la desigualdad de los sexos, denunciada por el feminismo, es política y no solamente antropológica, actual y no simplemente anacrónica e intemporal, si esto no se reconoce, es porque el ideal democrático implica lo universal y lo neutro más que lo particular y la diferencia, entonces, el universalismo, al considerarse un ideal es también una máscara. (Geneviève Fraisse, 1999)

¿Cómo plantearse, entonces, el espacio multicultural? Algunas autoras, como Sheyla Benhabib (2006) piensan que dentro de una democracia. Una democracia deliberativa y participativa, en donde las esferas públicas fueran transnacionales. Diferentes postulados teóricos recogen estas demandas e intentan dar respuesta desde diferentes posicionamientos. Paradigmas decolonialistas, poscolonialistas y multiculturalistas desde la transversalidad. En ellos se dan luchas para que se reconozcan derechos, así como desarrollan teorías políticas, en su particular, situada, y reflexiva mirada. Existen similitudes en sus planteamientos y demandas, pero a la vez, hay ciertos tópicos que oscurecen un maridaje posible, imposibilitando, quizá, la posibilidad del acuerdo. Ambos se fundamentan en el reconocimiento y valor de las diferencias, por ello me intereso, por discernir y explorar las distintas

${ }^{21}$ En Montenegro. (2011,115) 
explicaciones del mundo, desde su óptica académica, y así encontrar puntos de encuentro, de mestizaje cultural, en el que nos reconocemos y les reconocemos. Desde la subalternidad, y el poscolonialismo feminista se fundamenta este marco teórico dirigido hacia esas mujeres: invisibles, silenciadas, olvidadas, y subalternas que transitan los márgenes de las culturas, cosidas por numerosas opresiones y violencias.

"La cultura no hace a la gente. La gente hace la cultura. Si es verdad que no forma parte de nuestra cultura el hecho de que las mujeres sean seres humanos de pleno derecho, entonces podemos y debemos cambiar nuestra cultura" (Chimamanda Ngozi Adichie, 2015, 14)

\section{BIBLIOGRAFÍA}

AMORÓS, Celia; POSADA, Luisa (2007). Feminismo y Multiculturalidad. Madrid: Instituto de la Mujer.

BOLADERAS, Margarita; CAMPILLO, Neus (2001). Filosofía Social. La pluralidad cultural humana. Madrid: ed, Síntesis

ANZALDÚA, Gloria; BRAH, Avtar; HOOKS, Bell et al (2004). Otras Inapropiables. Feminismos desde las fronteras. Madrid: Traficantes de Sueños.

BENHABIB, Seyla (2006). Las reivindicaciones de la cultura. Igualdad y diversidad en la era global. Buenos Aires: Katz Editores.

BUTLER, Judith (2014). El género en disputa. El feminismo y la subversión de la identidad. Barcelona: Paidós.

CHAKRABARTY, Dipesh. (2000). Provincializing Europe. Postcolonial Thought and Historical Difference. Princeton: Princeton University Press.

DELEUZE, Gilles; FOUCAULT, Michel (2012). “Un diálogo sobre el poder” en, FOUCAULT, M. Un diálogo sobre el poder y otras conversaciones. Madrid: ed: Alianza Editorial.

FEMENÍAS, María Luisa (2005). "El feminismo postcolonial y sus límites”, en AMORÓS, C. DE MIGUEL, A. [Eds.]. Teoría feminista: de la Ilustración a la globalización. De los debates sobre el género al multiculturalismo. Madrid: Ed, Minerva Ediciones.

FOUCAULT, Michel (1999). El Orden Del Discurso. Barcelona: Tusquets. 
FRAISSE, Geneviève (1999) "Democracia exclusiva, república masculina", Hugo Quiroga et al. (comps.), Filosofías de la ciudadanía, Homo Sapiens Ediciones.

FRASER, Nancy (1995). Escalas de Justicia. Barcelona: Herder.

GROSFOGUEL, Ramón (2004). Race and Ethnicity or Racialized Ethnicities?: Identities within Global Coloniality. Ethnicities, 4(3), 315-336.

HARAWAY, Donna (1988). Situated Knowledges: The Science Question in Feminism and the Privilege of Partial Perspective. Feminist Studies, 14 (3), pp. 575-99.

HONNETH, Axel (1997). La lucha por el reconocimiento. Por una gramática moral de los conflictos sociales, Barcelona: Crítica.

JABARDO, Mercedes (ed., 2012). Feminismos negros. Una antología. Madrid: Traficantes de Sueños, Madrid.

KYMLICKA, Will (1996). Ciudadanía multicultural: una teoría liberal de los derechos de las minorías. Barcelona: Paidós.

LINEBAUGH, Peter; REDIKER, Marcus (2013). The Many-Headed Hydra. Sailors, Slaves, Commoners, and the Hidden History of the Revolutionary Atlantic. Ed. Beacon.

MALDONADO-TORRES, Nelson (2007). "Sobre la colonialidad del ser: contribuciones al desarrollo de un concepto". En: Santiago CastroGómez y Ramón Grosfoguel (eds.), El giro decolonial. Reflexiones para una diversidad epistémica más allá del capitalismo global (pp. 127-167). Bogotá: Iesco-Pensar-Siglo del Hombre Editores

MAYNARD, Mary (1994). "Race", Gender and the Concept of "Difference" in Feminist Thought. En: Haleh Afshar y Mary Maynard (Eds.), The Dynamics of "Race" and Gender. Some Feminist Interventions (pp. 9-25). London: Taylor \& Francis.

MEZZADRA, Sandro; Gayatri Chakravorty Spivak, Chandra Talpade Mohanty, Ella Shohat, Stuart Hall, Dipesh Chakrabarty, Achille Mbembe, Robert J. C. Young, Nirmal Puwar, Federico Rahola (2008). Estudios postcoloniales Ensayos fundamentales. Madrid: Traficantes de sueños.

MIGNOLO, Walter (2007). “El pensamiento decolonial: desprendimiento y apertura. Un manifiesto". En: Santiago Castro-Gómez y Ramón Grosfoguel (eds.) El giro decolonial. Reflexiones para una diversidad epistémica más allá del capitalismo global (pp. 25-46). Bogotá: Iesco-PensarSiglo del Hombre Editores.

MONTENEGRO Martínez, Marisela; GALAZ Valderrama, Caterine; YUFRA, Laura; MONTENEGRO Quitana, Karla. (2012). Dinámicas de subjetivación y diferenciación en servicios sociales para Mujeres inmigradas en la ciudad de Barcelona. Athenea Digital, 11(2), 113-132. 
NGOZI Adichie, Chimamanda (2015). Todos deberíamos ser feministas. disponible en: http://www.accionenredmadrid.org/wpcontent/ uploads / 2016/09/TODOS-DEBER\%C3\%8DAMOS-SER-

FEMINISTAS.pdf

QUIJANO, Aníbal; Wallerstein, Immanuel (1992). La americanidad como concepto, o América en el moderno sistema mundial. Revista Internacional de Ciencias Sociales. (134): 583-591.

QUIJANO, Anibal (1992). “Colonialidad y modernidad-racionalidad". En: Heraclio Bonilla (ed.), Los conquistados. 1492 y la población indigena de las Américas (pp. 437-447). Bogotá: Tercer Mundo Editores

RESTREPO, Eduardo; ROJAS, Alex (2010). Inflexión decolonial: fuentes, conceptos y cuestionamientos Colección Políticas de la Alteridad. Universidad del Cauca, Popayán, Colombia: Editorial Universidad del Cauca.

ROMERO BACHILLER, Carmen y GARCÍA-DAUDER, Silvia (2003). Saturaciones identitarias: de excesos, materialidades, significación y sus (in)visibilidades. Clepsydra, 2, 37-56.

ROMERO BACHILLER, Carmen (2006). Articulaciones Identitarias: Prácticas y representaciones de género y "raza"|etnicidad en "mujeres inmigrantes" en el barrio de Embajadores (Madrid). Tesis Doctoral sin publicar. Departamento de Sociología V (Teoría sociológica). Facultad de Ciencias Políticas y Sociología. Universidad Complutense de Madrid.

SPIVAK, Gayatri C. (2015). Crítica de la razón poscolonial. Hacia una historia del presente evanescente. Madrid: Ed. Akal.

SUÁREZ NAVAZ, Liliana; Hernández Castillo, Rosalva Aída (2008). Descolonizando el Feminismo: Teorías y Prácticas desde los Márgenes. Valencia: Cátedra.

TAYLOR, Charles (2010). Multiculturalismo y la politica del reconocimiento. México: Ed, Fondo de Cultura Económica.

WALZER, Michael (1993). Las esferas de la Justicia. Madrid: Fondo de Cultura Económica.

YOUNG, Iris (2000). La Justicia y la Política de la diferencia. Madrid: Cátedra. 